\title{
Patient Safety Culture and Application of Medication Safety Rules as Perceived by Nurses
}

\author{
Sabah Mahmoud Mahran, Sanaa Abd El Azim Ibrahim* \\ Nursing Administration Department, Faculty of Nursing, Port Said University, Port Said, Egypt
}

Email address:

sanaaahmed4@gmail.com (S. A. Ibrahim)

${ }^{*}$ Corresponding author

\section{To cite this article:}

Sabah Mahmoud Mahran, Sanaa Abd El Azim Ibrahim. Patient Safety Culture and Application of Medication Safety Rules as Perceived by Nurses. American Journal of Nursing Science. Vol. 5, No. 2, 2016, pp. 52-58. doi: 10.11648/j.ajns.20160502.13

Received: March 19, 2016; Accepted: March 25, 2016; Published: April 8, 2016

\begin{abstract}
Background: Patient safety is one of the biggest challenges in health care through providing safe, effective care, and one of the most significant areas of opportunity for improvement is medication safety, which is a top priority for patient harm prevention from medication errors. Aim: To assess nurses' perceptions concerning patient safety culture and the applicability of medication safety rules. Design: A descriptive correlational design was utilized. Settings: Six hospitals affiliated to the Ministry of Health from three governorates in Egypt. Participants: A sample of 421 nurses was chosen from the selected hospitals to participate in a structured questionnaire dealing with twelve dimensions to determine the level of nurses' awareness and their perceptions of patient safety culture, and the application of medication safety rules was measured by 99 questions under thirteen dimensions to collect the study data. The results revealed that only $26.13 \%$ of studied nurses indicated a high perception of overall patient safety culture, although $77.90 \%$ reported no adverse events during the last six months. Furthermore, $76.72 \%$ reported that they applied overall medication rules to prevent errors. Based on the study findings, it is recommended to develop strategies to disseminate patient safety culture and reduce punitive culture in health organizations, creating a climate of open communication and continuous learning. The development and optimizing of data collection and reporting systems and evidence-based programs for improving culture of patient safety in hospitals is necessary, and nurses must be encouraged to learn more about incident reports and how to write medication administration error reports.
\end{abstract}

Keywords: Patient Safety, Culture, Nurses, Medication Safety

\section{Introduction}

Safety is a serious component of health care quality, and health care organizations continually attempt to improve the safety of their services, with increasing recognition of the importance of establishing a safety culture. A culture of safety requires an understanding of the values, beliefs and norms about what is important in an organization and what attitudes and behaviors related to safety are supported, rewarded and expected (Rockville et al., 2012). The World Health Organization (WHO, 2014) identified patient safety practices as processes or structures that reduce the probability of adverse events resulting from exposure to the health care system across a range of diseases and procedures, while patient safety culture is the integration of safety thinking and practices in clinical activities (Bahrami et al., 2013). Patient safety culture is essentially a safeguard to produce a healthcare environment free of injury and harm caused by the processes of healthcare themselves.

Patient safety culture is a crucial global health concern, affecting patients in all health care settings, in developed and developing countries. WHO (2013) clarified that an estimated average of $10 \%$ of all inpatient admissions result in a degree of accidental patient harm, and it is estimated that up to $75 \%$ of these gaps in health care delivery are preventable. In addition to human suffering, unsafe health care exacts a heavy economic burden, with an estimated 5$10 \%$ of total health expenditure being diverted to patching up unsafe practices that resulted in patient harm. Generally such errors are attributable to system failures rather than individual negligence on the part of healthcare professionals, although they are often blamed as the last link in a faulty chain. Challenges facing patient safety globally are the 
inherent complexity of health care processes and the culture of denial and blame, in addition to inconsistencies in the reporting and learning systems, which inhibit the collection and dissemination of information in a meaningful way.

The African Region is particularly challenged by a lack of constructive assessments, comprehensive policies and strategies for patient safety, and health systems in Africa are in massive need of rapid evolution (Alkorashy, 2013; WHO, 2014). Patient safety and patient safety culture form the cornerstone of excellent health care delivery, whereas achieving patient safety and creating positive patient safety cultures requires ongoing efforts from every member of the healthcare team to keep patients safe from harm and adverse events when they are being cared for by a healthcare organization - avoiding and preventing patient injuries or adverse events resulting from the processes and techniques of health care delivery.

Patient safety culture is an organizational culture that creates a positive environment in which patient safety is likely to occur (Mardon et al., 2010; Ulrich \& Kear, 2014). It is well known that many adverse drug events such as medication administration errors (MAEs) occur within hospital settings, so organizational leadership needs to builds and support a culture of medication safety to be central to effective risk reduction and improved patient outcomes. In the context of medication management, this will involve incorporating medication safety issues into strategic and operational plans, and safety and quality risk registers, identifying specific risks and monitoring the impact of interventions (Australian Commission on Safety and Quality in Health Care, 2012). Medication management is known to be a critical component of patient safety across the care journey. Creating rules of medication safety is important to ensure that safe, reliable health care is adequately managed across that continuum. The medication system is one of the main areas of focus for any comprehensive patient safety program needed to be a culture among health team following settled medication rules to preserve patient health (Fracica et al., 2006). Numerous studies have identified the relationship between safety culture and professional attitudes and behaviors regarding error reporting, as reflected in mortality and other adverse events (Singer et al., 2009; Braithwaite \& Coiera, 2010; Mardon et al., 2010). In Egypt, patient safety culture still has many areas for improvement that need continuous evaluation and monitoring to attain a safe environment both for patients and health-care providers (Aboul-Fotouh et al., 2012).

\subsection{Aim}

To assess nurses' perceptions about patient safety culture and the applicability of medication safety rules.

\subsection{Objectives}

1. Determine the level of nurses' awareness and their perceptions of patient safety culture.

2. Assess nurses' perceptions about the applicability of medication safety rules.

3. Find out the relationship between level of patient safety culture and the applicability of medication safety rules.

\subsection{Research Questions}

1. What is the level of nurses' awareness and their perceptions about safety culture?

2. What are nurses' perceptions about the applicability of medication safety rules in hospitals?

3. Is there a relationship between nurses' perceptions about patient safety culture and the applicability of medication safety rules?

\section{Methods}

\subsection{Design}

A descriptive correlational design was utilized.

\subsection{Study Settings and Participants}

The study was conducted in six governmental hospitals affiliated to the Ministry of Health from three governorates in Egypt, namely El Zohor Hospital, Port Said General Hospital, and Port-Fouad General Hospital in the Port Said Governorate; the Cancer Institute at Damietta in Damietta Governorate; and Belkass General Hospital and Sherbien General Hospital in the Mansoura Governorate. The participants consisted of 421 nurses working in inpatient units with at least one year of experience in their work setting. Systematic random sampling technique was used to select the nurses. The estimated number of nurses required for the purposes of data analysis was based on equations by Brown and Hollander (1977).

\subsection{Variables and Instruments}

To collect the study data, the questionnaire sheet comprised three parts. Part I was developed by the researchers to collect data related to job and personal characteristics of studied nurses, such as their age, gender, qualifications and experience. Part II was adopted from the Hospital Survey on Patient Safety Culture (HSPSC, 2012), to determine the level of nurses' perceptions of safety culture. This part included 12 dimensions covering 44 items.

The safety culture dimensions for the unit level included seven dimensions: Supervisor/manager expectations and actions promoting patient safety (4 items); Teamwork within units (4 items); Organizational learning continuous improvement (3 items); Communication openness (3 items); Feedback and communication about error (3 items); Nonpunitive response to errors ( 3 items); and Staffing (4 items).

The safety culture dimensions for the hospital level included three dimensions: Hospital management support for patient safety (3 items); Teamwork across hospital units (4 items); Hospital handoffs and transitions (4 items).

There were four outcome dimensions: Frequency of event reporting (3 items); Overall perceptions of safety (4 items). 
The former was separated two dimensions, the first of which concerned the number of events reported during the previous six months (1 item) and the second of which dealt with degree of patient safety in the hospitals (1 item), as clarified in Figures 1 and 2.

A total of 15 items were negatively worded and were thus reversely coded before data analysis. Questionnaire items required respondents to answer on a five-point Likert scale in terms of agreement (strongly agree, agree, neither, disagree, strongly disagree) or frequency (always, most of the time, sometimes, rarely, never). Level of nurses' perception related to patient safety were calculated by a statistician; low level of nurses perception was estimated as $<60 \%$, while high level estimated as $\geq 60 \%$.

Part III was the Self-Assessment Questionnaire (SAQ) to assay nurses' perceptions of the applicability of medication safety rules at hospitals adopted from the Emergency Care Research Institute (ECRI, 2008) and modified by the researchers, who canceled two dimensions with nine items covering the role of the pharmacist (because the study targets are nurses). The application of medication safety rules was measured by thirteen dimensions covering 90 items. The dimensions measured were: Leadership support (7 items); Policies and procedures (5 items); Storage ( 8 items); Medication ordering and transcription (3 items); Illegible handwriting, verbal or telephone orders, and abbreviation (6 items); Medication preparation and dispensing (9 items); Medication administration (5 items); Medication monitoring (3 items); High risk medications (5 items); Medication safety strategies (14 items); Medications reconciliation (3 items); Education (12 items); and Medications event reporting (10 items). Most of these items contained sub-items. The reported questionnaire required nurses to reflect the applicability of medication safety rules through responses of 'yes' (scored 2), 'need improvement' (scored 1) or 'not applicable' (scored 0).

\subsection{Procedures}

The questionnaire was translated into Arabic by the researchers, and the translated version was subsequently validated by an English professor from Faculty of Arts of the English Department at Port Said University. A panel of five faculty staff members from the nursing administration department revised the tool to pretest for clarity and readability, and according to their comments some slight modifications were made. The tool's reliability was measured using Cronbach's Alpha, for which patient safety culture scored 0.740 and medication safety rules 0.987 .

To ascertain the clarity and applicability of the tools and the time needed to fill the questionnaire a pilot study was carried out on $10 \%$ of the sample size taken from the same study population, but not from the study sample size. The required modifications were identified and conducted based on analysis of the pilot test results, which also indicated that the time needed for nurses to fill the questionnaire sheet was approximately 40-50 minutes. After obtaining the official permission from the hospital administrators to conduct the study (see below) and after finalization of the data collection tool, data were collected over a four-month period from September to December 2013. The researchers met the nurses during three shifts and explained to them the purpose of the study, and the oral consent of each eligible nurse was obtained before their participation. Nurses were given the self-administered written questionnaire sheet and asked to fill it out; some completed it immediately, while others gave another fixed date to complete it.

\subsection{Ethical Consideration}

Written approval was sought and obtained from the studied hospitals' administrators, prior to conducting the study (there being no formally designated ethics committees in either institution at the time of conducting the study). Precautionary measures were taken to safeguard the study of nurses. Before the interview, oral consent forms were obtained from nurses and their confidentiality and anonymity was strictly maintained through affixing a code number to each individual questionnaire.

\section{Results}

The study sample comprised 421 nurses, aged from 20 to more than 50 years. The majority of them were females, and most of them held nursing school diplomas. Twofifths had 5-10 years of experience in their current position.

\subsection{Patient Safety Culture}

The summarized scores on the 12 dimensions of patient safety culture are shown in Table 1 . The highest level of safety culture dimensions on the unit level (76.72\%) was for teamwork within units, followed by organizational learning for continuous improvement (75.06\%). Staffing shortage, non-punitive response to errors and absence of communication openness were the main obstacles to patient safety as perceived by nurses $(96.44 \%, 83.85 \%$ and 68.17 , respectively). Only $26.13 \%$ of studied nurses recorded high perceptions for overall patient safety culture. Figure 1 clarifies the number of reported negative events as an outcome of patient safety cultural dimensions. According to negative events in the last six months, $77.90 \%$ of nurses reported that no events occurred, while $9.30 \%$ of nurses reported one to two events and $4.30 \%$ reported six to ten. Figure 2 clarifies patient safety as expressed by nurses as an outcome of safety culture dimensions. Less than half of nurses judged that the patient safety was very good, while $35 \%$ of nurses valued it as passing, and $5 \%$ considered the patient safety to be poor. 
Table 1. Safety culture level as perceived by nurses $(n=421)$.

\begin{tabular}{|c|c|c|c|c|c|}
\hline & & \multicolumn{4}{|c|}{ Nurse perceptions } \\
\hline \multirow{2}{*}{\multicolumn{2}{|c|}{ Safety culture dimensions }} & \multicolumn{2}{|c|}{ High $\geq 60 \%$} & \multicolumn{2}{|c|}{ Low $<60 \%$} \\
\hline & & No & $\%$ & No & $\%$ \\
\hline \multirow{7}{*}{ (Unit) } & Supervisor/manager expectations \& actions promoting patient safety & 197 & 46.79 & 224 & 53.21 \\
\hline & Teamwork within units & 323 & 76.72 & 98 & 23.28 \\
\hline & Organizational learning continuous improvement & 316 & 75.06 & 105 & 24.94 \\
\hline & Communication openness & 134 & 31.83 & 287 & 68.17 \\
\hline & Feedback and communication about error & 227 & 53.92 & 194 & 46.08 \\
\hline & Non-punitive response to errors & 68 & 16.15 & 353 & 83.85 \\
\hline & Staffing & 15 & 3.56 & 406 & 96.44 \\
\hline \multirow{3}{*}{ (Hospital) } & Hospital management support for patient safety & 171 & 40.62 & 250 & 59.38 \\
\hline & Teamwork across units & 174 & 41.33 & 247 & 58.67 \\
\hline & Hospital handoffs and transitions & 95 & 22.57 & 326 & 77.43 \\
\hline \multirow{2}{*}{$\begin{array}{l}\text { Outcome } \\
\text { dimensions }\end{array}$} & Frequency of events reported & 171 & 40.62 & 250 & 59.38 \\
\hline & Overall perceptions of patient safety & 153 & 36.34 & 268 & 63.66 \\
\hline \multicolumn{2}{|c|}{ Overall patient safety culture } & 110 & 26.13 & 311 & 73.87 \\
\hline
\end{tabular}

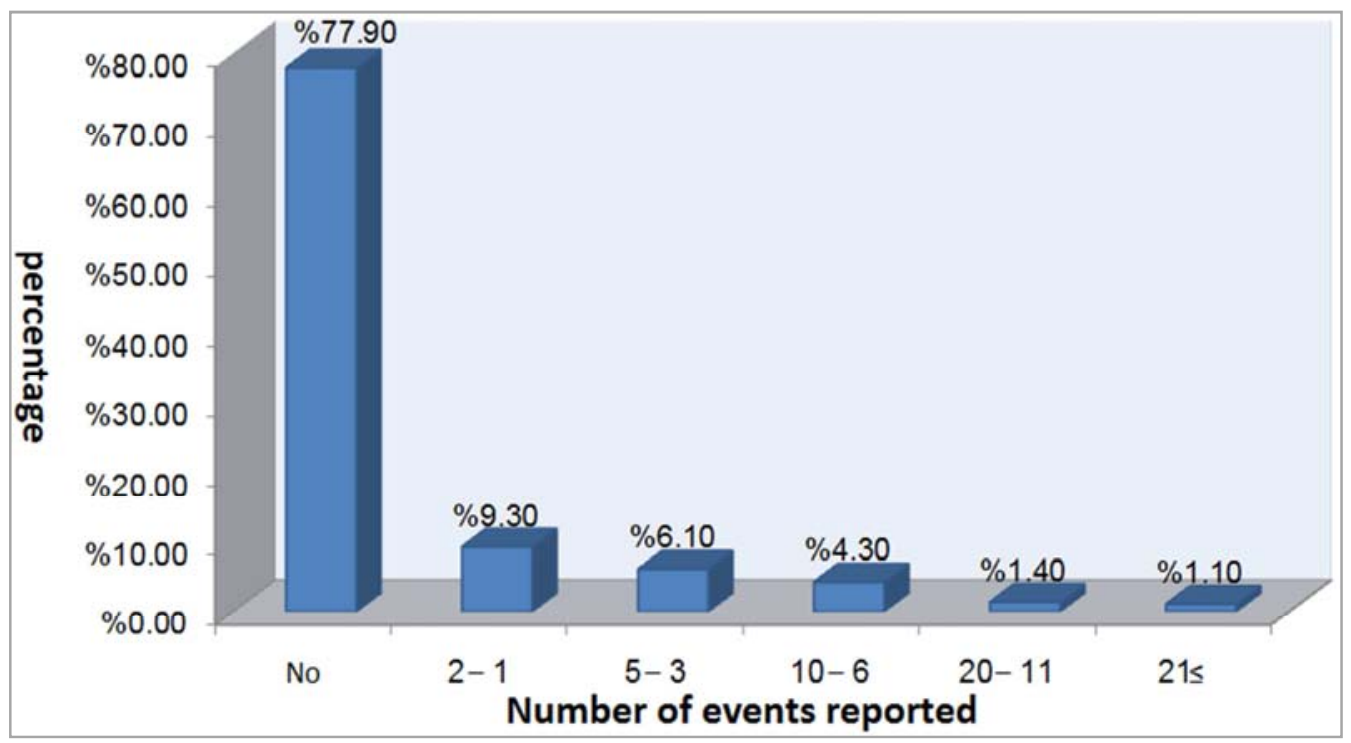

Figure 1. Number of reported negative events.

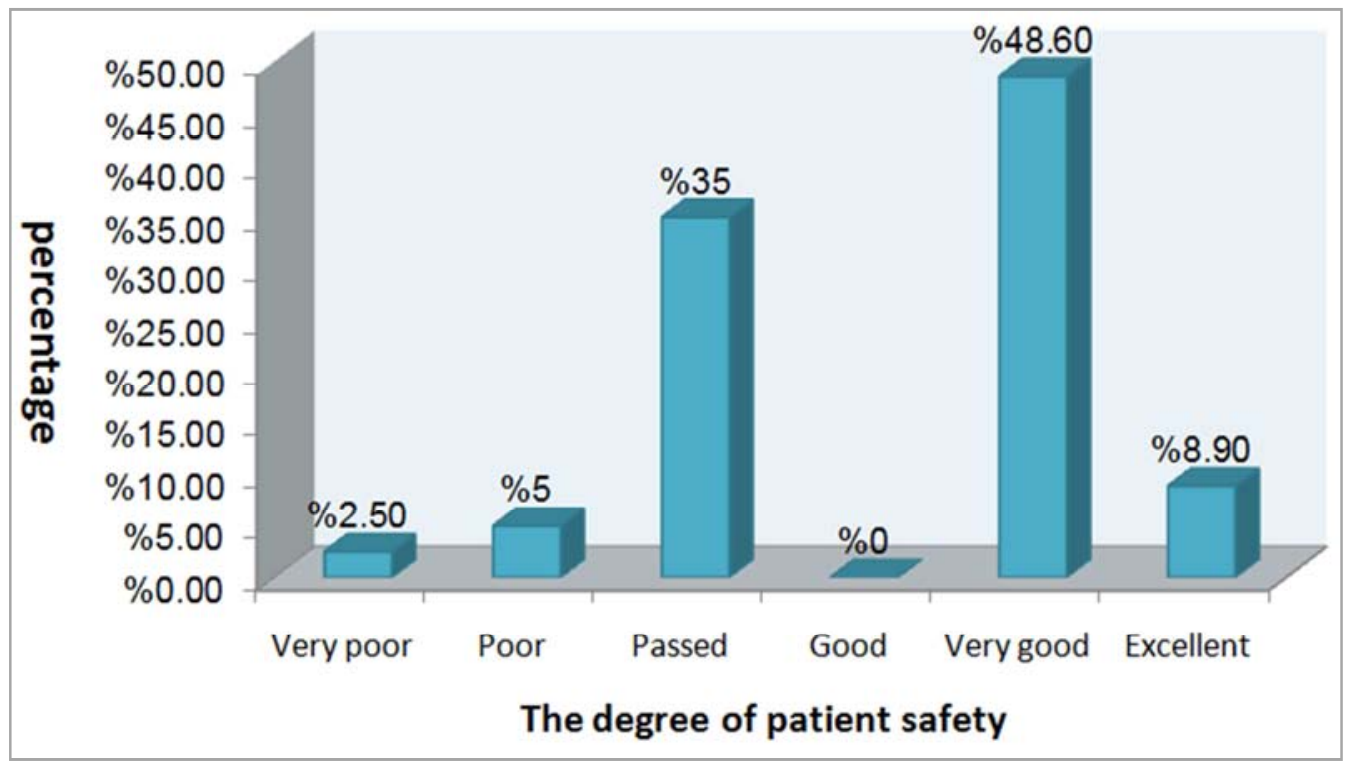

Figure 2. Degree of patient safety as expressed by nurses $(n=421)$. 


\subsection{Medication Application Rules}

rules of medication administration, monitored medication, illegible handwriting, verbal or telephone orders, and abbreviation, medication ordering and transcription, storage, high risk medications and policies and procedures (92.16\%), (87.17\%), (82.19\%), (77.43\%), (70.31\%), (66.04\%), and $61.04 \%$ respectively). Medication event reporting was reported to be applied by $58.19 \%$ of nurses. More than threefourths $(76.72 \%)$ applied overall medication rules to prevent errors. Regarding nurses' need for education about medication safety information and so on, $57.01 \%$ agreed that their training needed improvement.

Table 2. Application of medication safety rules among nurses $(n=421)$.

\begin{tabular}{|c|c|c|c|c|c|c|}
\hline \multirow{2}{*}{$\begin{array}{l}\text { Medication rules } \\
\text { related }\end{array}$} & \multicolumn{2}{|c|}{ Not applied } & \multicolumn{2}{|c|}{$\begin{array}{l}\text { Need } \\
\text { improvement }\end{array}$} & \multicolumn{2}{|c|}{ Applied } \\
\hline & No. & $\%$ & No. & $\%$ & No. & $\%$ \\
\hline Leadership support & 26 & 6.18 & 88 & 20.90 & 307 & 72.92 \\
\hline Policies and procedures & 18 & 4.28 & 146 & 34.68 & 257 & 61.04 \\
\hline Storage & 18 & 4.28 & 107 & 25.41 & 296 & 70.31 \\
\hline $\begin{array}{l}\text { Medication ordering and } \\
\text { transcription }\end{array}$ & 35 & 8.31 & 40 & 9.50 & 346 & 82.19 \\
\hline $\begin{array}{l}\text { Illegible handwriting, } \\
\text { verbal or telephone } \\
\text { orders, and abbreviation }\end{array}$ & 9 & 2.14 & 86 & 20.43 & 326 & 77.43 \\
\hline $\begin{array}{l}\text { Medication preparation } \\
\text { and dispensing }\end{array}$ & 24 & 5.70 & 165 & 39.19 & 232 & 55.11 \\
\hline $\begin{array}{l}\text { Medication } \\
\text { administration }\end{array}$ & 2 & 0.48 & 31 & 7.36 & 388 & 92.16 \\
\hline Medication monitoring & 9 & 2.14 & 45 & 10.69 & 367 & 87.17 \\
\hline High risk medications & 23 & 5.46 & 120 & 28.50 & 278 & 66.04 \\
\hline $\begin{array}{l}\text { Medication safety } \\
\text { strategies }\end{array}$ & 45 & 10.68 & 152 & 36.11 & 224 & 53.21 \\
\hline $\begin{array}{l}\text { Medications } \\
\text { reconciliation }\end{array}$ & 31 & 7.36 & 83 & 19.72 & 307 & 72.92 \\
\hline Education & 21 & 4.99 & 240 & 57.01 & 160 & 38.00 \\
\hline $\begin{array}{l}\text { Medications event } \\
\text { reporting }\end{array}$ & 18 & 4.28 & 158 & 37.53 & 245 & 58.19 \\
\hline $\begin{array}{l}\text { Overall rules to prevent } \\
\text { errors }\end{array}$ & 0 & 0.0 & 98 & 23.28 & 323 & 76.72 \\
\hline
\end{tabular}

\subsection{Relation Between Safety Culture and Application of Medication Rules}

Table 3 shows the statistically significant difference between nurses' perception regarding safety culture and application of medication safety rules.

Table 3. Correlation between safety culture and application of medication safety rules among nurses.

\begin{tabular}{lll}
\hline Correlation & \multicolumn{3}{l}{ Patient safety culture } \\
\hline Application of medication safety rules & $\mathrm{r}$ & $\mathrm{p}$ \\
& 0.218 & $<0.001^{*}$ \\
\hline
\end{tabular}

r: Pearson coefficient $*$ : Statistically significant at $\mathrm{p} \leq 0.05$

\section{Discussion}

Safety culture needs to be embedded as a routine lifestyle among health care providers when dealing with patients, to fulfill the human rights of the latter before considering the professional responsibilities to preserve life and prevent harm, especially in terms of avoiding adverse events that remain common among hospitalized patients. The current study assessed nurses' perceptions of patient safety culture and the applicability of medication safety rules. The prominent findings that dealt with safety culture dimensions on a unit level were related to teamwork within units, which highlights the importance of collaboration among nurses, organizational learning for continuous improvement, feedback and communication about error. Staffing shortage, non-punitive response to errors and absence of communication openness were the obstacles to patient safety as perceived by nurses. These results corroborate those of AlAhmadi (2009), who found that organizational learning was the safety culture dimension with the highest positive response, while the key areas that need improvement in public hospitals include handoffs and transitions, communication openness, staffing.

Non-punitive response to error is a shared dimension of safety culture, matching the results of Al-Ahmadi (2009). Aboul-Fotouh et al. (2012) found the lowest mean composite positive score was for the dimension of non-punitive response to error. Also, Bahrami et al. (2013) asserted that the punitive response to error remains entrenched, despite acknowledgement of inevitable changes in patient safety culture. The consequent low reporting of adverse events is thus a common weakness in the studied hospitals, in line with global literature. Catastrophic results regarding overall safety culture revealed that about three-quarters of nurses had a low level of safety culture perception, which means that the health area is inherently at high risk. This finding supports Huang et al. (2010), who mentioned that culture scores were mostly low to moderate and varied across units. However, it contradicts Dodek et al. (2011), who asserted that culture domain scores were generally favorable.

In terms of reported negative events, the results showed that more than three-quarters of studied nurses reported that no events occurred within the previous six months, while only $9.30 \%$ of nurses reported one to two events and $4.30 \%$ reported six to ten. This suggests the underestimation of adverse events, and might be related to staff feeling that their mistakes and event reporting is held against them, and that mistakes may be kept in their personnel file. This reflects the low level of safety culture among nurses highlighted by Ulrich and Kear (2014). Moreover, Tomazoni et al. (2015), added that low adherence to reporting is possibly being related to various factors including punitive culture, work overload and feelings of fear, which precipitate the underreporting of errors without a just culture, offering no opportunities (for individuals and the organization) to learn and improve. Conversely, when errors are reported it is possible to plan actions to prevent them from 
happening again, through the detection of the organizational and cultural factors, problems in the provision of care and system defense barriers.

Regarding patient safety as expressed by nurses, results highlighted that less than half of nurses judged that patient safety was very good. Despite the critical areas evidenced, the majority of the subjects rated patient safety as "acceptable" or "very good" in the intensive care units. A study that aimed to examine the safety culture, performed with 3,779 professionals from hospitals in the Netherlands, the USA and Taiwan showed that the majority of the subjects of the North American hospitals considered the safety to be excellent $(25 \%)$ or very good $(48 \%)$, whereas those from the Netherlands and Taiwan mostly considered safety to be acceptable; in any case, all over the world patient safety needs to be the foremost concern for health care providers, and they must be protected from any danger or exposure to risk (Wagner et al., 2013).

Ahmed et al. (2011) found that staff nurses perceived patient safety culture more positively than negatively. According to this study's findings, more than three-fourths of nurses applied overall medication rules to prevent the errors, through medication administration, monitor medication, illegible handwriting, verbal or telephone orders, and abbreviation, medication ordering and transcription, storage, high risk medications and policies and procedures. This reflects that the most recurrent activities undertaken by nurses for patients are medication administration, which leads to mastery level in the same skills, and increases their attention to medication administration rules, in addition to their abilities to read the poor handwriting of doctors' medication orders. According to the Health Care Association of New Jersey (2007), to avoid medication error, clear written orders include signed orders that may be handwritten is needed, with the avoidance of abbreviations; alternatively, the Institute for Safe Medication Practices guidelines can be used. Nurses must note all illegible, incomplete or otherwise questionable orders and immediately seek clarification from the prescriber before transcribing or dispensing the medication orders, properly medications. Clearly it would be more efficient to use electronic labeling systems where possible.

Medication should be placed in a proper location, kept from spoiling. However, despite the relatively rudimentary nature of related skills, the key area that needed improvement as identified in this study was training and education about medication safety. In this concern, the Centers for Disease Control and Prevention (CDC, 2008) emphasized that welltrained nurses play a vital role in providing safe and highquality patient care, but the absence of training programs and of procedural manuals in the unit and inadequate supervision affects nurses' performance and undermines the quality of patient care (Fahmy et al., 2010). The study results highlighted the statistical significance difference between nurses' perceptions regarding safety culture and the application of medication safety rules. This study evidence matches that of ElDin \& ElAal (2013), who denied a relationship between perceived safety climate and barriers to MAE reporting.

\section{Conclusion}

Study concluded that a low level of safety culture was found among nurses. Staffing shortage, non-punitive response to errors and absence of communication openness were the main barriers to patient safety reported by nurses. Most nurses claimed to apply overall medication rules to prevent errors, but the key area needing improvement was training and education about medication safety. Based on the study findings, it is recommended to develop strategies to disseminate a patient safety culture and reduce the punitive culture, creating a climate of open communication and continuous learning. The development and optimization of data collection and reporting systems and developing evidence-based programs for improving culture of patient safety in hospitals will encourage nurses to learn more about the incident reports and how to write MAE reports in particular. Such process-level amendments can ultimately revolutionize patient safety culture in Egyptian hospitals in the long term.

\section{References}

[1] Aboul-Fotouh AM, Ismail NA, Ez Elarab HS, Wassif GO (2012). Assessment of patient safety culture among healthcare providers at a teaching hospital in Cairo, Egypt. Eastern Mediterranean Health Journal, 18(4): 372-377.

[2] Ahmed, NG, Adam SM, Abd Al-Moniem II (2011). Patient safety: Assessing nurses' perception and developing an improvement plan. Life Science Journal, 8(2): 53-64.

[3] Al-Ahmadi TA (2009). Measuring patient safety culture in Riyadh's hospitals: A comparison between public and private hospitals. Journal of the Egyptian Public Health Association, 84(5-6): 479-500.

[4] Alkorashy HA (2013). Factors shaping patient safety management in the Middle East hospitals from nursing perspective: A focus group study. Middle-East Journal of Scientific Research, 15(10): 1375-1384.

[5] Australian Commission on Safety and Quality in Health Care (ACSQHC) (2012). Safety and Quality Improvement Guide Standard 4. Sydney: ACSQHC.

[6] Bahrami MA, Montazeralfaraj R, Chalak M (2013). Patient safety culture challenges: Survey results of Iranian educational hospitals. Middle-East Journal of Scientific Research, 14(5): 641-649.

[7] Braithwaite J, Coiera E (2010). Beyond patient safety Flatland. Journal of the Royal Society of Medicine, 103(6): 219-225.

[8] Brown BW, Hollander M (1997). Statistics: A biomedical introduction. New York: Wiley.

[9] Centers for Disease Control and Prevention (2008). Campaign to prevent antimicrobial resistance in healthcare settings: 12 steps [online]. Available at: http://www.cdc.gov/ drug resistance/ healthcare/.. [last accessed 10 March 2016]. 
[10] Dodek PM, Wong H, Jaswal D, Heyland DK, Cook DJ, Rocker GM, Kutsogiannis D J, Dale C, Fowler R, Ayas NT (2011). Organizational and safety culture in Canadian intensive care units: Relationship to size of intensive care unit and physician management model. Journal of Critical Care, 27(1): 11-7.

[11] Emergency Care Research Institute (2008). Self-assessment questionnaires 10: Continuing care risk management. Available

at
https://www.ecri.org/components/CCRM/Pages/default.aspx

[12] Fahmy AM, Khalifa MA, Abdalla SM, Abdel-Rahman SM (2010). Measuring nurses' compliance with patients' safety measures during hemodialysis at Minia University and General Hospital. Zagazig Nursing Journal, 6(11): 68-82.

[13] Fracica P, Lafeer M, Minnich M, Fabius R (2006). Patient safety checklist: Keys to successful implementation. The Physician Executive, 32(4): 46-53.

[14] Health Care Association of New Jersey (HCANJ) (2007). Medication Management Guideline. Trenton, NJ: HCANJ.

[15] Patient Safety Group (2012). Hospital survey on patient safety culture [online]. Available at: $\mathrm{http}: / /$ www.patientsafetygroup.org/survey/index.cfm?sample= 1 [last accessed 18 January 2016].

[16] Huang DT, Clermont G, Kong L, Weissfeld LA, Sexton JB, Rowan KM, Angus DC (2010). Intensive care unit safety culture and outcomes: US multicenter study. International Journal of Quality Health Care, 22(3): 151-61.

[17] Mardon RE, Khanna K, Sorra J, Dyer N, Famolaro T (2010). Exploring relationships between hospital safety culture and adverse events. Journal of Patient Safety, 6(4): 226-232.
[18] Rockville W, Sorra J, Famolaro T, Dyer N, Nelson D, Smith, SA (2012). Hospital Survey on Patient Safety Culture: User comparative database report. Washington, DC: US Department of Health and Human Services, Agency for Healthcare Research and Quality. AHRQ Publication No. 120017.

[19] Singer S, Lin S, Falwell A, Gaba D, Baker L (2009). Relationship of safety climate and safety performance in hospitals. Health Services Research, 44(2), 399-421.

[20] Tomazoni A, Rocha PK, Kusahara DM, Souza AI, Macedo TR (2015). Evaluation of the patient safety culture in neonatal intensive care. Text Context Nursing, 24(1): 161-9.

[21] Ulrich B, Kear T (2014). Patient safety and patient safety culture: Foundations of excellent health care delivery. Nephrology Nursing Journal, 41(5): 447-456.

[22] Wagner C, Smits M, Sorra J, Huang CC (2013). Assessing patient safety culture in hospitals across countries. International Journal of Quality Health Care, 25(3): 213-21.

[23] World Health Organization (2013). Learning from error: Role of reporting error, components of a reporting system, sources of information about patient safety, national reporting systems, characteristics of successful reporting systems. Geneva: WHO.

[24] World Health Organization (2014). Guide for Developing National Patient Safety Policy and Strategic Plan. Geneva: WHO, Patient Safety Unit.

[25] Zein ElDin YK, Abd ElAal NH (2013). The relationship between perceived safety climate, nurse s' work environment and barriers to medication administration errors. Life Science Journal, 10(1): 950-961. 